\title{
STUDIES ON THE CONTROL OF PLANT CELL ENLARGEMENT BY CELLULAR PARAMETERS
}

\section{Final Report}

Robert E. Cleland

Department of Botany

University of Washington

Seattle, WA 98195

July 1,1987 - June 30,1990
DOE/ER/ $13830--2$

DE92 004838

December 6, 1991

\begin{abstract}
PREPARED FOR THE U.S. DEPARTMENT OF ENERGY UNDER GRANT DE-FG06-88ER 13830.
\end{abstract}

This report was prepared as an account of work sponsored by the United States Government. Neither the United States nor the U.S. Department of Energy nor any of their employees, nor any of their contractors, subcontractors, or their employees, make any warranty, express or implied, or assumes any legal liability or responsibility for the accuracy, completeness or usefulness of any of the information, apparatus, product or process disclosed, or represents that its use would not inf ringe privately-owned rights.

\section{D'SCLAIMER}

This report was prepared as an account of work sponsored by an agency of the United States Government." Neither the United States Government nor any agency thereof, nor any of their employees, makes any warranty, express or implied, or assumes any legal liability or responsibility for the accuracy, completeness, or usefulness of any information, apparatus, product, or process disclosed, or represents that its use would not infringe privately owned rights. Reference herein to any specific commercial product, process, or service by trade name, trademark, manufacturer, or otherwise does not necessarily constitute or imply its endorsement, recommendation, or favoring by the United States Government ur any agency tiicreof. The views and opinions of authors expressed herein to not necersarily state or reflect those of the United States Government or any agency thereof.

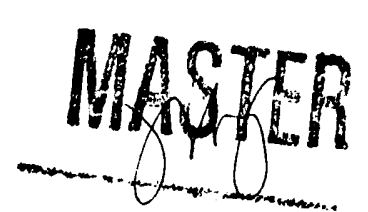




\section{FINAL REPORT}

The overall goal of this grant was to conduct research that would illuminate the mechanisms by which the plant hormone auxin induces plant cells to enlarge. A large body of knowledge already existed concerning this process. To begin with, it had been demonstrated, primarïy by this laboratory during previous grant periods, that the effect of auxin is to cause a loosening of the cell wall, which is followed by turgor-driven wall expansion and water uptake. The wall contains a series of load-bearing wall bonds which must be cleaved in order to loosen the wall. The identification of these load-bearıng bonds is one goal of this research.

A number of years ago we proposed that an initial action of auxin is to cause cells to excrete protons, and that the resulting acidification of the apoplast activated enzymes responsible for wall loosening. Evidence for this "acid-growth theory" has been obtained in this lab during previous grant periods. Evidence has also been obtained that indicates that the proton excretion is due to an enhanced activity of the plasma membrane $\mathrm{H}^{+}$-ATPase. A critical question is how auxin activates this enzyme.

During the first year of this grant studies were carried out on the relationship between the lipids in the plasma membrane and the activity of the PM-ATPase. As these studies are describec in some detail in the Progress Report of June 20, 1988, and are published in two papers in Plant Physiology, they will not be described here.

A second project concerned the reversibility of acid-induced cell wall loosening. This work is described in the Progress Report of 6/88. Because of the limited budget the second year, no further work on this project has been carried out, and the work is not yet sufficiently advanced so as to be published.

The third project concerned the role of wall calcium as part of load-bearing wall bonds. It has long been thought that apoplastic calcium crosslinks carboxyl groups in the wall pectic substances and stiffens the walls. This "calcium-bridge hypothesis" is an attractive one and has been widely accepted, although there was really little direct evidence for it. We examined the role of calcium-bridges as load-bearing bonds in soybean hypocotyl cell walls in two ways. The first was to measure the viscoelastic extensibility of walls after addition of exogenous calcium or removal of endogenous calcium. These studies showed that endogenous calcium can act as load-bearing crosslinks, but that almost three-quarters of the wall calcium must be removed before there is any sizable wall loosening. These results were described in the Progress Report of $6 / 88$ and have been published in a paper in Planta.

The second approach was to determine if removal of wall calcium from walls while under tension resulted in wall extension, as predicted if the calcium-bridges were load-bearing bonds. Initial experiments made use of the calcium chelator EGTA to extract wa!l calcium. There is a problem with EGTA, however; as it removes calcium it replaces it with protons, with the result that the walls become acidic. Since acidic conditions are known to cause wall loosening, it is difficult to be certain that any effect of EGTA is actually due to removal of calcium from the wall. Nevertheless, the results seemed to indicate that removal of wall calcium did not loosen cell walls. These preliminary results were described in more detail in the Progress Report of 6/88. 
- We were directed to scale back the research during this second, final yea: of the grant, and concentrate on the calcium studies. This we have done. During this final year we have concentrated on four research projects. Each will be described briefly.

\section{Calcium Crosslinks as Load-bearing Bonds in Soybean Hyoocotyl Walls,}

The first project was to complete our study of the possible role of calcium crosslinks as load-bearing bonds in soybean hypocotyl cell walls. If the calcium bridges are load-bearing, removal of wall calcium without changing the wall $\mathrm{pH}$ should cause extension of isolated walls under tension. To test this, soybean hypocotyl walls were bisected longitudinally to facilitate entry of chemicals, then were frozen and thawed. The half-sections were placed under a constant load of $20 \mathrm{~g}$ in a pH 6.0 buffer and the extension was recorded with a position transducer. After 20 minutes, the solution was changed to one whose $\mathrm{pH}$ was 4.5 or to one at $\mathrm{pH} 6$ containing $1 \mathrm{mM}$ Quin-2. Quin-2 is a calcium chelator which can extract wall calcium without changing the apoplastic $\mathrm{pH}$. The extension over the next 6 hours was then recorded. The $\mathrm{pH} 4.5$ solution causes the isclated walls to undergo extensive elongation; this process is called facilitated creep, and is caused by the acid-mediated cleavage of load-bearing cell wall bonds. If calcium crosslinks are load-bearing bonds, Quin-2 should also be effective in causing facilitated creep

It was first shown that Quin-2 effectively and rapidly extracts the calcium from these walls. Within 2 hours the calcium content was reduced to less than $10 \%$ of the initial value. However, treatment of walls under tension with Quin-2 caused only a small amount of facilitated creep. These data demonstrate that wall calcium of soybean hypocotyl walls do not form significant numbers of load-bearing crosslinks.

The possibility has been raised that cell wall loosening might involve an acidmediated cleavage of calcium-bridges. Since information was not available about the extent to which calcium might be solubilized from cell walls when the apoplast is acidified in response to auxin, the following experiment was performed. Epidermal layers were removed from soybean hypocotyls and the walls were isolated by freezing/thawing. These epidermal strips were then incubated for 4 hours in solutions of varying $\mathrm{pH}$ between 3 and 7 , after which the walls were washed with water. The remaining wall calcium was extracted and measured. The results are shown in Fig. 1. In the absence of auxin the apoplastic $\mathrm{pH}$ is around 6, while in the presence of auxin the $\mathrm{pH}$ decreases to 4.5-5.0. Fig. 1 shows that incubation at pH 4.5 removes only $20 \%$ of the wall calcium as compared with a pH 6 solution. As this is far lower than the amount removed by Quin-2, it provides evidence that acidification of the walls cannot be causing wall loosening by solubilizing wall calcium.

This research was included in a paper published in Planta in 1990 and in a paper published in the Riverside Symposium volume in 1990.

\section{Wall Calcium and the Apoplastic $\mathrm{pH}$.}

Both $\mathrm{H}^{+}$and $\mathrm{Ca}^{2+}$ bind tightly to the $\mathrm{COO}^{-}$groups of cell wall pectic chains. At any time, the amount of carboxyl groups to which calcium is bound will depend on the relative concentration of $\mathrm{H}^{+}$(i.e., $\mathrm{pH}$ ) and $\mathrm{Ca}^{2+}$ in the apoplastic solution. Knowirg the amount of calcium bound to the walls in vivo, if should be possible to determine either the apoplastic $\mathrm{pH}$ or the apoplastic free $\mathrm{Ca}^{2+}$ concentration if the other is known. We have used this fact to estimate the actual $\mathrm{pH}$ in the vicinity of 
the wall polymers.

The epidermal layers (which are believed to control the rate of hypocotyl elongation) were stripped off of soybean hypocotyls, frozen, and the walls were separated from the cytoplasm. They were then incubated in $20 \mathrm{mM} \mathrm{K}$-phosphate buffers, pH 3.0 to 7.0, with varying concentrations of calcium. After 4 hours, the walls were washed well, dried, and their calcium content was determined.

When the external solution contained calcium, the walls took up or lost calcium, depending on the pH. An example is shown in Fig. 2 for calcium roncentrations between 30 and $200 \mathrm{uM}$ and pHs between 3.0 and 4.0. For each calcium concentration there is a pH at which the solution calcium is in equilibrium with the wallbound calcium. A plot of this equilibrium $\mathrm{pH}$ vs the $\log$ of the $\mathrm{Ca}^{2+}$ concentration gives a straight line (Fig. 3). The points on this line are the possible combinations of apoplastic calcium and $\mathrm{pH}$ that could have existed in vivo so as to give the observed wall calcium.

Dr. Thomas Björkman used calcium-specific microelectrodes to measure the apoplastic calcium concentration of soybean hypocotyl walls. The values obtained varied considerably, but the average value was between 100 and $200 \mathrm{uM}$. The curve in Fig. 3 indicates that at this apoplastic calcium concentration, the apoplastic pH must have been about 3.5 in order to be in equilibrium with the wall-bound calcium. This value is a real surprise, as it is at least one $\mathrm{pH}$ unit lower than any recorded $\mathrm{pH}$ value for the apoplast of a stem.

There are several possible ways to explain these data. One possibility is that the measured apoplastic $\mathrm{Ca}^{2+}$ concentration is at least ten-fold too high. All available evidence is contrary to this conclusion. The second is that the apoplastic calcium was not, in fact, in equilibrium with the wall-bound calcium. Measurements of the rapidity with which walls equilibrate with solution calcium suggests that this is unlikely. The third possibility is that the $\mathrm{pH}$ value is correct, but that it is not the free space (WFS) pH value but the Donnan Free Space (DFS) pH. The DFS is the area around fixed negative charges in which soluble cations are accumulated so as to cause electroneutrality. These cations can be protons or any other cation, but the two most effective Donnan cations are $\mathrm{H}^{+}$and $\mathrm{Ca}^{2+}$. Sentenac \& Grignon have calculated that because of the bound carboxyl groups in the wall that the DFS will have a pH that can be as much as $3 \mathrm{pH}$ units lower than that of the surrounding solution, the WFS. Since the pectic carboxyl groups will be in the DFS, the equilibrium between bound and free calcium will be determined by the DFS pH. If the wall-loosening enzymes are associated with the wall polymers, they too will be in the DFS. These results explain, at least in part, why it is difficult to "set" the $\mathrm{pH}$ around the wall-loosening enzymes by adjusting the $\mathrm{pH}$ of the external soiution.

The pH of the DFS will depend on at least three factors. The first is the concentration of free carboxyl groups in the wall. Carboxyls that are esterified do not affect the DFS $\mathrm{pH}$, but any demethylation of pectins by pectin methylesterase will increase the carboxyl concentration. The second factor is the pH of the WFS; the lower the WFS pH, the lower will be the DFS pH. The third factor is the concentration of cations in the apoplastic solution. As these increase, the concentration of free protons "immobilized" in the DFS decreases; i.e., the DFS pH rises. The most effective of the common cations is $\mathrm{Ca}^{2+}$. A decrease in the free $\mathrm{Ca}^{2+}$ content in the apoplast will cause the DFS $\mathrm{pH}$ to decrease. We have proposed as a possible mode of action of auxin that auxin might cause inward-rectifying calcium channels to open, causing the apoplastic $\mathrm{Ca}^{2+}$ to fall and the DFS $\mathrm{pH}$ to decrease. This, in turn, would lead to wall loosening and thus cell elongation. 
This research is currently being written up for publication.

\section{Mechanism of Calciurn-induced Inhibition of Cell Elongation.}

It has long been known that calcium ions can inhibit auxin-induced cell elongation in plants. This inhibition has usually be ascribed to the formation of stiffening calcium-briclges in the cell walls. As demonstrated by the research in the first project, this possibility is no longer a real possibility. But what is the alternative?

It is well known that inhibition of auxin-induced cell elongation by calcium is rapid and cals be almost total. Surprisingly, it appears that no one has bothered to follow the kinetics of calcium inhibition for longer periods of time. Our prediction was that the severity of the inhibition would increase with time, as the calcium penetrated the tissue and became more concentrated at its site of action. To test this, soybean hypocotyl sections were abraded to facilitate entry of the calcium and incubated in IAA for 2 hours. $\mathrm{CaCl}_{2}$ was then added and the growth was measured over the next 8 hours. The results for a typical experiment are shown in Fig. 4. To our surprise we found that growth was almost completely and immediately inhibited by concentrations of $\mathrm{Ca}^{2+}$ of $0.3 \mathrm{mM}$ or above. However, after a period of time that was dependent on the $\mathrm{Ca}^{2+}$ level, growth resumed. The length of time of the severe inhibition of growth was dependent on the $\mathrm{Ca}^{2+}$ concentration, varying from 0.5 to 3 hours. Once growth resumed, the resulting growth rate was also calcium-dependent. At lower concentrations (0.3-0.5 mM) the initial rate was completely restored. At $1 \mathrm{mM} \mathrm{Ca}{ }^{2+}$ the rate was slightly reduced, and with higher levels of calcium the rate was progressively reduced. After we had completed this research we learned that Dr. Mike Evans (Ohio State U.) has obtained nearly identical kinetics for calcium-inhibition of corn root growth.

These data indicate that calcium has two distinct effects on growth. The first is a strong and immediate inhibition of growth, which persists for a limited period. This is followed by a second inhibition which is less severe, requires higher calcium cuncentrations to be effective, and persists for much longer periods of time. Our interpretation of these data is as follows. The initial severe inhibition of growth is due to the fact that the calcium ions displace protons from the DFS, resulting in an increase in DFS pH. This, in turn, inhibits the wall loosening process. The system then begins to readjust to the original situation by increasing the rate of proton excretion. The excreted protons displace calcium ions from the DFS and growth resumes. The resumed growth occurs at a rate dependent on the rate of proton excretion and the level of solution calcium.

These data have been incorporated into a paper which will be submitted for publication shortly.

4. The Role of Acid Responsiveness of Soybean Hypocotyl Walls in the Control of Growth.

The first step in auxin-induced cell elongation is the excretion of protons from cells into the apoplast, followed by acid-induced cell wall loosening. The rate of elongation depends on the two factors; the $\mathrm{pH}$ of the apoplast, and the capacity of the walls to be loosened by the acid (CAWL). Most studies on the role of wall acidification in the control of growth have focused on the effect of growth factors to affect the apoplastic pH. However, CAWL also has the potential for controlling the rate of wall loosening; changes in CAWL can cause changes in growth 
rate without any change in apoplastic pH. CAWL can be measured in several ways. The method most used to date is to measure the ability of isolated cell walls to undergo extension in vitro when under conditions of constant tension and constant pH. When isolated walls are subjected to tension at $\mathrm{pH} 7$ they undergo a viscoelastic extension which is largely completed in 20-30 minutes. If the solution $\mathrm{pH}$ is then lowered to 4.5 , additional extension then occurs due to acid-induced wall loosening. The extension occurs first as a burst of extension (ExE phase) followed by a prolonged period of linear extension (LE phase). This extension can be described by the equation:

$$
\mathrm{L}=\mathbf{a}-\mathbf{a} \cdot \mathbf{e}^{-\mathbf{k} t}+\mathbf{c} \cdot t
$$

where $L$ is the amount of extension, $a$ is the total extension during the exponential phase (ExE), $k$ is the rate constant for ExE, $c$ is the rate of linear extension (LE) and $t$ is the time. In theory, a change in CAWL can involve a change in either of the two extension parameters, a or c.

In this project, the relationship between the parameters $a, c$ and the capacity of soybean hypocotyl sections to grow was determined. In the first phase, the hypocotyls of 3-day old red light-grown soybean seedlings were marked 3 and $18 \mathrm{~mm}$ below the hook. At varying times over the next $24 \mathrm{~h}$, the growth was determined and sections were harvested and frozen. After thawing, the acid-extension parameters a and c were determined. As shown in Fig. 5, the growth rate of the marked region of the hypocotyl remained nearly constant for about 16 hours and then fell sharply. The parameter a (EXE) showed a nearly identical profile. On the other hand, the LE parameter c showed a quite different profile, as it lell sharply during the first 8 hours. These data suggest that the rate of hypocotyl growth in vivo might have been controlled by the a parameter.

To test this idea further, sections were cut from 3-day old hypocotyls and incubated in water for 0 to 12 hours. At varying times sections were incubated for 4 hours with 1 uM fusicoccin or $10 \mathrm{uM}$ IAA in order to determine their capacity for acid-induced growth. They were then frozen, thawed, and their acid extension parameters a and $c$ were determined. During the 12 hour incubation in water the sections continually lost the capacity for fusicoccin-induced growth. Since FC is believed to act entirely via an acid-extension mechanism this indicates that removal of the sections from the intact plant causes a loss of CAWL. When the FC-induced growth was plotted as a function of the parameters $a$ and $c$ it was found that there was a close correlation between a and the FC-induced growth (fig. 6), but only a poor correlation between $\mathrm{c}$ and CAWL.

Severai conclusions can be drawn from these data. The first is that the decline in the growth rate of soybean hypocotyl cells in vivo (.r in the ability of isolated sections to grow in response to IAA or FC is due to a loss of the walls to undergo the exponential phase of acid-extension. This suggests that CAWL may be far more important in controlling cell elongation than has previously been recognized.

These data have been incorporated into a manuscript which is in the final stages of preparation. 


\section{Publications Resulting firom this Grant}

Virk. S.S. \& R.E. Cleland (1988) Calcium and the mechanical properties of soybean hypocotyl cell walls: possible role of calcium and protons in cell-wall loosening. Planta 176: 60-67.

Virk, S.S. \& R.E. Cleland (1990) The role of wall calcium in the extension of cell walls of soybean hypocotyls. Planta 182: 559-564.

Cleland, R.E. (1988) The primary mechanism of auxin action. In: Physiology and Biochemistry of Auxins in Plants. M. Kutacek, R.S. Bandurski \& J. Krekule, eds. Academia Praha: Prague. pp. 109-116.

Cleland, R.E. (1990) Proton export, ATPase and hormone action. In: Molecular Aspects of Hormonal Regulation of Plant Development. M. Kutachek, M.C. Elliott and I. Machackova eds. SPB Academic Publishing: Hague. pp. 185-194.

Sandstrom, R.P. \& R.E. Cleland (1989) Comparison of the lipid composition of oat root and coleoptile plasma membranes. Lack of short-term change in response to auxin. Plant Physiol. 90: 1207-1213.

Sandstrom, R.P. \& R.E. Cleland (1989) Selective delipidation of the plasma membrane by surfactants. Enrichment of sterols and activation of ATPase. Plant Physiol. 90: 1524-1531.

Cleland, R.E., S.S. Virk, D. Taylor \& T. Björkman (1990) Calcium, cell walls and growth. In: Calcium in Plant Growth and Development. R.T. Leonard \& P.K. Hepler, eds. Amer. Soc. Plant Physiol: Rockville. pp. 9-16.

Cleland, R.E. \& S.S. Virk (1989) The role of wall pH and wall calcium in the control of cell wall extension. In: Plant Water Relations and Growth under Stress. M. Tazawa, M. Katsumi, Y. Masuda \& H. Okamoto, eds. MYU K.K.: Osaka. pp. 283-290. 

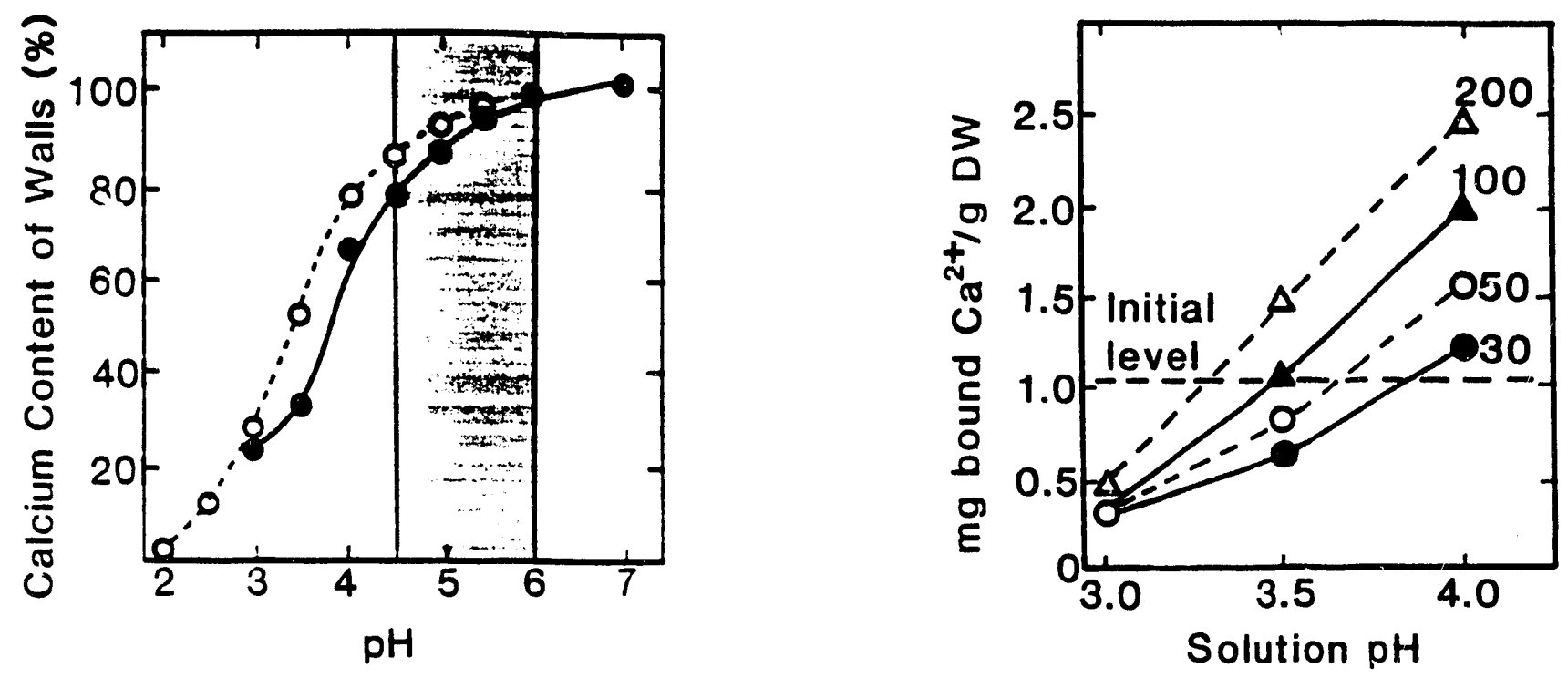

Figure 1 (left). Effect of external pH on the solubilization of wall-bound calcium ions. Epidermal strips were isolated from soybean hypocotyl sections, frozen-thawed, and then incubated for 4 hours in $20 \mathrm{mM} \mathrm{K}$-phosphate buffers at the indicated $\mathrm{pH}$. The amount of wall-bound calcium at the end of this incubation was then measured. The calcium content after a pH 6.0 incubation was set at $100 \%$ (980 ug Ca ${ }^{2+} / \mathrm{g} \mathrm{DW}$ walls). In the absence of auxin the wall $\mathrm{pH}$ is about 6.0, while in its presence it is about 4.5. The physiological conditions are those under the shaded area.

Figure 2 (right). The effect of external $\mathrm{pH}$ and $\mathrm{Ca}^{2+}$ on the uptake or loss of wallbound calcium. Epidermal strips from soybean hypocotyls were incubated in $\mathrm{K}$ phosphate buffers, $\mathrm{pH} 3.0$ to 4.0 , and with $\mathrm{Ca}^{2+}$ concentrations between 30 and $200 \mathrm{uM}$. After 4 hours, the amount of wall-bound calcium was measured. The initial level of calcium prior to incubation was $1.05 \mathrm{mg} / \mathrm{g} \mathrm{DW}$ Assuming that the wall was in equilibrium with the apoplastic free $\mathrm{Ca}^{2+}$, the possible combinations of solution $\mathrm{Ca}^{2+}$ and $\mathrm{pH}$ are given by the points were the lines cross the "initial" line. 

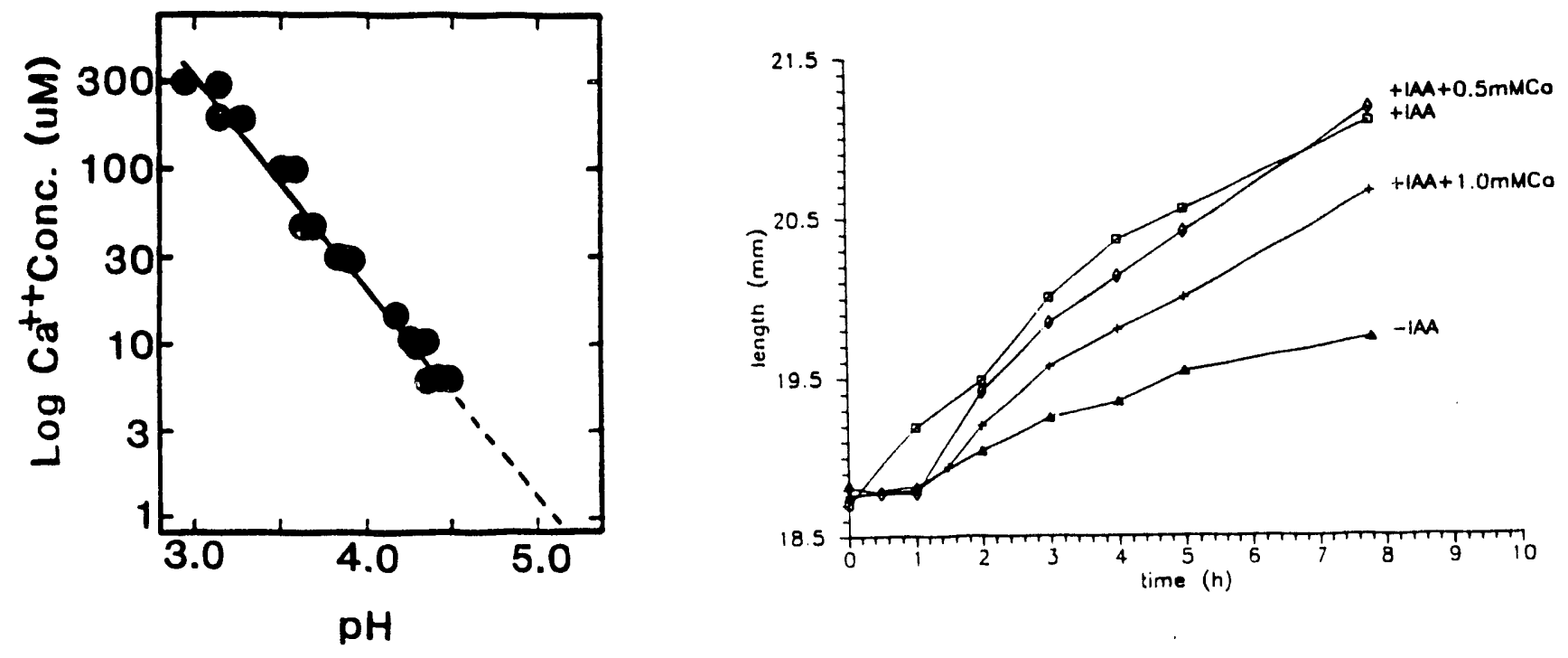

Figure 3 (Left) Conditions of apoplastic free $\mathrm{Ca}^{2+}$ and $\mathrm{pH}$ that could have existed in soybean hypocotyl walls assuming that the walls were in equilibrium with the apoplastic solution. The points are derived from experiments such as shown in Fig. 2. They indicate that if the apoplastic free $\mathrm{Ca}^{2+}$ was $200 \mathrm{uM}$, as measured with calcium microelectrodes, the apoplastic pH at the carboxyl groups must have been about 3.5 if equilibrium conditions existed.

Figure 4 (Right) Effect of solution calcium on the kinetics of auxin-induced growth of soybean hypocotyl sections. Sections were presncubated for 2 hours with IAA, then 0.5 or $1.0 \mathrm{mM} \mathrm{CaCl}$ was added to certain sections. The growth over the next 8 hours was measured. It can be seen that both calcium concentrations cause an immediate and severe inhibition of growth, but that after 1 or 1.5 hours growth resumes. 

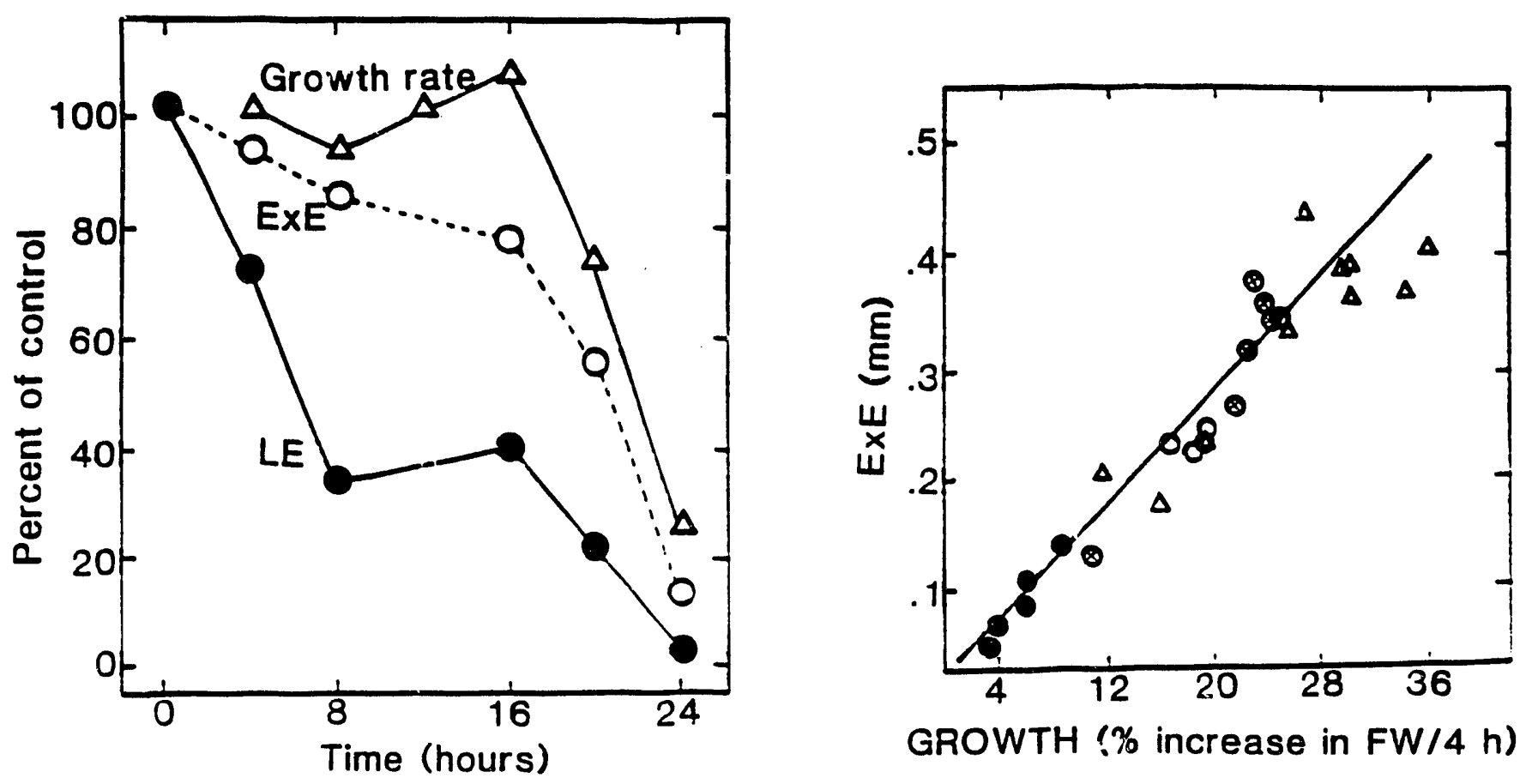

Figure 5 (Left). The relationship between the in vivo growth rate of a marked section of intact soybean hypocotyls and the capacity of the walls to undergo acid-induced extension. The in vitro acid-extension is characterized by the facilitated-creep parameters for the exponentia! phase (ExE) and the linear phase (LE) of extension. These data show that there is a good correlation between the growth rate and ExE, but not with LE.

Figure 6 (Right). The relationship between the ability of isolated soybean hypocotyl sections to grow in response to fusicoccin and the in vitro acidextension parameter ExE. Sections were incubated for up to 10 hours in water, then 1 UM FC was added and the growth over the next 4 hours was measured. The sections were then frozen-thawed, and the acid-facilitated creep was then measured to give ExE values. 

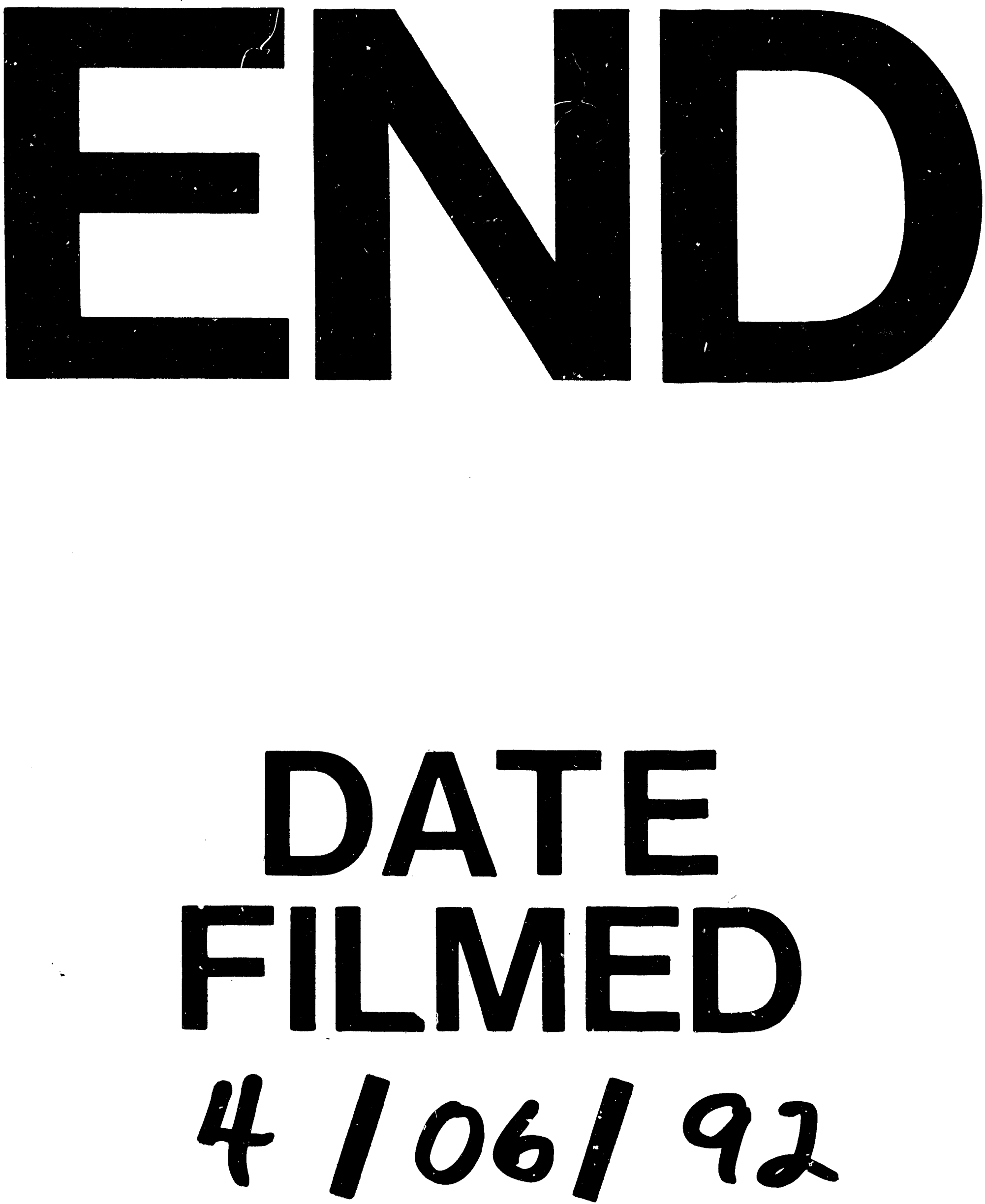
